\title{
PERIPHERAL VENOUS POOLING AND LEFT ATRIAL PRESSURE PULSE IN MITRAL DISEASE
}

\author{
BY \\ P. G. F. NIXON \\ From the Department of Thoracic Surgery, the General Infirmary at Leeds, England, and the Clinic of Surgery, \\ National Heart Institute, Bethesda, Maryland, U.S.A. \\ Received December 18, 1959
}

Considerable hæmodynamic changes occur when venous tourniquets are applied to the extremities in man. As much as $890 \mathrm{ml}$. of blood may be trapped in ten minutes (Ebert and Stead, 1940) and the cardiac output falls (McMichael and Sharpey Shafer, 1944; Warren et al., 1945; Fitzhugh et al., 1953), and pressure is reduced in the jugular vein (Warren and Stead, 1943), right atrium, and pulmonary artery (Estes and McWhorter, 1949; Doyle et al., 1951). In the limb not subjected to venous occlusion arteriolar narrowing and a reduction in venous pressure precede venoconstriction (Wood and Eckstein, 1958). The rise in right atrial temperature is consistent with a diminished return of relatively cool blood from the periphery (Carlsten and Grimby, 1958). Renal plasma flow and glomerular filtration rate are reduced (Fitzhugh et al., 1953). The third heart sound of rapid early diastolic left-ventricular filling may be abolished in normal subjects (Sloan and Wishart, 1953) and in patients with severe heart disease (Leonard et al., 1958a). In hypertensive cardiovascular disease the atrial gallop becomes smaller in amplitude and moves closer to the first heart sound (Leonard et al., 1958b).

The changes in pressure that occur in the left side of the heart as a result of peripheral venous pooling in man have not so far been described. The purpose of this communication is to describe the changes in left atrial pressure that may occur when venous tourniquets are applied to the thighs of patients with mitral valve disease, and to discuss their significance in relation to the diagnostic use of left atrial pressure pulses.

\section{MATERIAL AND Methods}

In 16 patients suffering from rheumatic heart disease, left atrial pressure pulses were recorded before and after the application of venous tourniquets to the legs. The diagnosis of the cardiac condition was made from consideration of clinical, cardiographic, and radiological data, and from the results of left heart catheterization and, where operation was performed, from the findings at cardiotomy. Ten patients were considered to have pure mitral stenosis, and in one of these aortic valve disease was also present. Two patients suffered from mitral stenosis and regurgitation, and in one of these the aortic and tricuspid valves were diseased. Mitral regurgitation was dominant in the remaining four patients. Congestive heart failure had not occurred in any patient within three months of the present investigation.

All patients were studied in the fasting state after premedication with omnopon $20 \mathrm{mg}$. and scopolamine $0.4 \mathrm{mg}$., or with demerol, 50 to $75 \mathrm{mg}$., and nembutal $100 \mathrm{mg}$. To catheterize the left atrium the method described by Ross (1959) was used in one case, the method of Morrow et al. (1957b) in two, and the method of Allison and Linden (1955) in the remainder. Care was taken to exclude damping artefacts from air bubble and blood clot. Square wave pressure pulses were applied to the recording system before and after catheterization as a check against such artefacts. All pressures were measured during an expiratory pause to avoid respiratory distortion of the base line.

As soon as the patient appeared to be relaxed a control left atrial pressure pulse was recorded, and then broad pneumatic tourniquets previously placed around the upper thighs were rapidly inflated to a pressure of $80-85 \mathrm{~mm}$. Hg. After a period varying from $2 \frac{1}{2}$ to 6 minutes the left atrial pressure was measured again. 
The mean atrial pressure was obtained by planimetry. The pressure at the apex of the $v$ wave and at the $z$ point was noted. The ratios of pressure at the $v$ apex to the mean pressure (Connolly and Wood, $1957)$ and to the pressure at $z$ were calculated. The rate of $y$ descent related to the pressure at $v(R y / v)$ (Owen and Wood, 1955); and the rate of $y$ descent during the first tenth of a second related to the mean pressure (Ry 0.1/mean) (Morrow et al., 1957a) were calculated. In every case the results presented are the mean of values obtained from three consecutive heart-cycles. Heart rates were obtained from the electrocardiogram.

\section{RESULTS}

The table records the age, sex, diagnosis, and heart rhythm of the sixteen patients studied. The duration of venous pooling between measurements of atrial pressure is shown. Control mean, $v$, and $z$ pressures are listed, and the degree of alteration obtained after venous pooling is shown as a percentage of the control value. Control values and percentage alteration after pooling are tabulated for the ratio of $v$ peak to mean pressure; for the rate of $y$ descent related to $v$ peak pressure (Owen and Wood, 1955); and for the rate of descent during the first tenth of a second of $y$ related to the mean atrial pressure (Morrow et al., 1957a). Illustrative left atrial pressure pulses from Cases 2, 5, 7, and 9 are shown in Fig. 1.

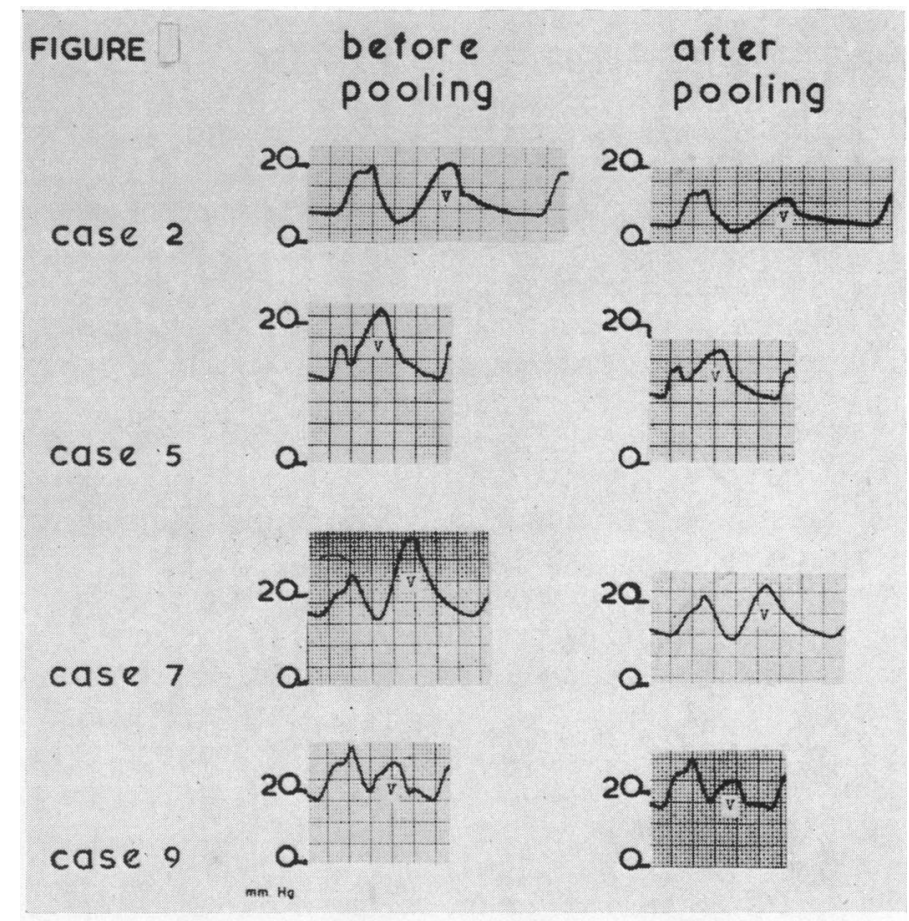

Fig. 1.-Examples of left atrial pressure pulses, recorded before and after peripheral venous pooling by tourniquet. Scale: $\mathrm{mm}$. $\mathrm{Hg}$. Paper speed $50 \mathrm{~mm} / \mathrm{sec}$. Zero level=sternal angle.

Pulse Rate and Heart Rhythm. Twelve patients showed a decrease in pulse rate during the period of pooling, and four an increase. In thirteen the alteration in pulse rate was less than 10 per cent of the control value. The presence of atrial fibrillation appeared to make no difference to the effect of pooling on the left atrial pressure pulse.

Left Atrial Mean Pressure. Values ranging from 5 to $32 \mathrm{~mm}$. $\mathrm{Hg}$ were obtained before venous pooling began. With one exception a fall in mean pressure occurred after the application of 
tourniquets. The decrease measured 40 per cent or more of the control value in three patients and 20 per cent or more in nine. The average decrease was 25 per cent.

Pressure at the Apex of the $v$ Wave. Control values ranged from 7 to $46 \mathrm{~mm}$. Hg. After the application of tourniquets the pressure at the apex of $v$ fell in every case. The smallest reduction measured 16 per cent of the control value, the greatest 43 per cent. The average fall in $v$ peak pressure was 27 per cent.

Pressure at the $z$ Point. A reduction was obtained in every case but one. Control values ranged from 9 to $29 \mathrm{~mm}$. Hg. The minimum, maximum, and average falls obtained after pooling were 6,34 , and 16 per cent of the control value respectively.

Ratio of $v$ Peak to $z$ Point Pressure. The lowest control value obtained was 0.7 and the highest 5.3. After pooling, the ratio did not alter in two cases, and increased by 1 per cent in another. In the remaining thirteen cases decreases ranged from 1 to 36 per cent of the control values, the average being 18 per cent.

Ratio of v Peak to Mean Left Atrial Pressure. In eleven cases this ratio decreased by 12 per cent or less, and in one case by 33 per cent. No alteration was obtained in one patient, and in 3 an increase occurred.

Rate of $y$ Descent Measured Throughout Diastole and Related to $v$ Peak Pressure $(R y / v)$. In the ten patients with mitral stenosis control values fell within the limits 1.0 to $2 \cdot 8$. $R y / v$ measured 1.06 and 1.04 in the two patients with mitral stenosis and regurgitation. In Cases 13 to 16 with predominant mitral regurgitation the values for $R y / v$ were $0 \cdot 5,0 \cdot 5,3 \cdot 9$, and $2 \cdot 3$.

Large and unpredictable alterations occurred after the application of tourniquets. In one case $R y / v$ increased by 42 per cent, and in another by 12 per cent. In one there was no change. In the remainder the average fall in $R y / v$ was 26 per cent of the control value (range $2 \%$ to $64 \%$ ).

Rate of $y$ Descent During the First Tenth of a Second Related to Mean Atrial Pressure (Ry $0 \cdot 1$ $\sec (M)$. Control values fell within the limits 0.13 to 0.75 in patients with pure mitral stenosis and between 0.4 and 1.54 in cases of dominant regurgitation. After venous pooling $R y 0 \cdot 1 / \mathrm{sec} / \mathrm{M}$ increased by 27 per cent in one patient, and decreased in the remainder by amounts ranging from 6 to 65 per cent of the control value. The average reduction was 23 per cent.

\section{Discussion}

The form of the left atrial pressure pulse as a whole is dependent upon numerous factors: the volume-elasticity characteristics of the chamber, the pressure exerted by surrounding structures, blood volume and flow rate and viscosity, heart rate, left ventricular end-diastolic pressure, and the functional state of the mitral valve. The form of the $v$ wave in particular is a measure of the rise of pressure occurring in the atrium during the period of mitral valve closure. If other factors remained constant the pressure at $v$ would depend upon flow into the atrium, whether the flow came from the pulmonary veins or from the left ventricle through an incompetent mitral valve.

In the present study it was possible to reduce the flow of blood from the pulmonary veins into the left atrium without altering the anatomical state of the mitral valve in a series of patients suffering from mitral stenosis and/or regurgitation. The reduction in the height of the $v$ wave that followed this procedure was relatively greater than the fall in pressure at $z$. The $y$ descent became less steep, whether it was measured for its full length and related to the pressure at $v$, or measured for the first tenth of a second and related to left atrial mean pressure.

Personal experience and published reports have suggested that various combinations of mitral stenosis and regurgitation may be associated with similar left atrial pressure pulses (Connolly and Wood, 1957; Morrow et al., 1957; Rubin and Shah, 1958; Hamer et al., 1959). The present study shows that a variety of pressure pulses may occur in a given patient without any alteration in the structure of the diseased mitral valve. The observed reduction in the height of the $v$ wave and slope of the $y$ descent that followed reduction in the flow of circulating blood supports the suggestion that acceleration and viscous friction are important factors in the formation of a pressure pulse from pulsatile flow in an elastic vessel (Hamer et al., 1959; Peterson, 1954). 
The fact that left atrial mean, $v$ and $z$ pressures, and the rate of $y$ descent may alter greatly with variations in blood flow must be taken into account when it is intended to use the pressure pulse as a parameter in the study of mitral valve disease. For example, the observation of a relatively higher $v$ wave and a steeper $y$ descent after mitral valvotomy may mean only that the cardiac output has increased, and may not signify the production of regurgitation by operation.

It is worthwhile to note that the ratio of $v$ peak pressure to left atrial mean pressure remained relatively constant during venous pooling. Possibly changes in this ratio will prove to be the best guide to alterations in mitral valve function in a particular patient. It should be emphasized that this suggestion has no bearing on the value of the ratio in diagnosing mitral regurgitation, for in the present series three patients with gross regurgitation had smaller ratios than those obtained in some patients with pure mitral stenosis.

In clinical practice venous tourniquets may be applied to the limbs in the treatment of patients suffering from acute pulmonary venous congestion (Hayward, 1955). The present study offers some indication of the extent to which left atrial pressure may be reduced by short periods of peripheral venous pooling in patients with mitral valve disease.

TABLE

Results obtained in 16 Patients with Mitral Disease

\begin{tabular}{|c|c|c|c|c|c|c|c|c|c|c|c|c|c|c|c|c|c|}
\hline \multirow{2}{*}{ ֶֻ } & \multirow{2}{*}{ 恖 } & \multirow{2}{*}{ 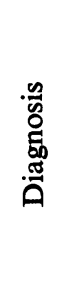 } & \multicolumn{2}{|c|}{$\begin{array}{c}\text { Heart } \\
\text { rate } \\
\text { (per min.) }\end{array}$} & \multirow{2}{*}{ 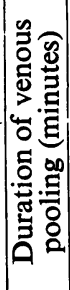 } & \multicolumn{2}{|c|}{$\begin{array}{c}\text { Pressure } \\
\text { mean }\end{array}$} & \multicolumn{2}{|c|}{$\begin{array}{c}\text { Pressure } \\
\text { at apex of } v\end{array}$} & \multicolumn{2}{|c|}{$\begin{array}{l}\text { Pressure } \\
\text { at } z\end{array}$} & \multicolumn{2}{|c|}{$v /$ mean } & \multicolumn{2}{|c|}{$R y / v$} & \multicolumn{2}{|c|}{$\underset{\text { mean }}{R y(0 \cdot 1) /}$} \\
\hline & & & $\begin{array}{l}\overline{0} \\
\text { : } \\
\text { O }\end{array}$ & 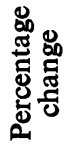 & & 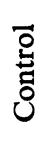 & 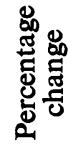 & $\begin{array}{l}\text { 올 } \\
\text { 류 }\end{array}$ & 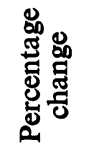 & 옹 & 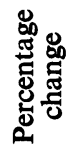 & 苞 & 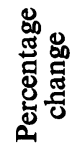 & $\begin{array}{l}\overline{0} \\
\text { : }\end{array}$ & 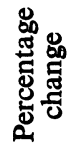 & $\begin{array}{l}\overline{0} \\
\text { ț }\end{array}$ & 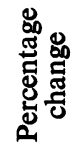 \\
\hline $\begin{array}{l}1 . \\
2 . \\
3 . \\
4 . \\
5 . \\
6 . \\
7 . \\
8 . \\
9 . \\
10 . \\
11 . \\
12 . \\
13 . \\
14 . \\
15 . \\
16 .\end{array}$ & $\begin{array}{l}45 \\
20 \\
40 \\
39 \\
43 \\
37 \\
49 \\
33 \\
33 \\
35 \\
30 \\
40 \\
52 \\
42 \\
36 \\
50\end{array}$ & & \begin{tabular}{|r|}
83 \\
67 \\
95 \\
83 \\
117 \\
59 \\
83 \\
68 \\
111 \\
127 \\
67 \\
92 \\
125 \\
136 \\
154 \\
102
\end{tabular} & $\begin{array}{r}-8 \\
-4 \\
-4 \\
-14 \\
+5 \\
-2 \\
-2 \\
-25 \\
-6 \\
-2 \\
-2 \\
+27 \\
0 \\
+5 \\
-2 \\
-8\end{array}$ & $\begin{array}{c}5 \\
5 \\
6 \\
6 \\
4 \\
3 \\
5 \\
6 \\
4 \\
2 \cdot 5 \\
3 \\
4 \\
5 \\
3 \\
5 \\
5\end{array}$ & $\begin{array}{r}5 \\
12 \\
12 \\
14 \\
16 \\
17 \\
21 \\
24 \\
24 \\
26 \\
21 \\
29 \\
11 \\
20 \\
23 \\
32\end{array}$ & $\begin{array}{l}+24 \\
-42 \\
-15 \\
-45 \\
-24 \\
-28 \\
-23 \\
-40 \\
-13 \\
-33 \\
-19 \\
-17 \\
-24 \\
-18 \\
-20 \\
-8\end{array}$ & $\begin{array}{l}7 \\
20 \\
11 \\
18 \\
23 \\
24 \cdot 5 \\
33 \\
32 \cdot 5 \\
28 \\
28 \\
28 \\
42 \\
12 \\
43 \\
36 \\
46\end{array}$ & $\begin{array}{l}-3 \\
-2 \\
-2 \\
- \\
-1 \\
= \\
=2 \\
= \\
- \\
- \\
= \\
-\end{array}$ & $\begin{array}{r}12 \\
24 \\
20 \\
12 \\
28 \\
25 \\
23 \\
24 \\
17 \\
8 \\
15 \\
29\end{array}$ & $\begin{array}{r}0 \\
-34 \\
-17 \\
-31 \\
-21 \\
-18 \\
-15 \\
-12 \\
-7 \\
-22 \\
-12 \\
-24 \\
-10 \\
-6 \\
-17 \\
-11\end{array}$ & $\begin{array}{l}1 \cdot 38 \\
1.14 \\
1.08 \\
1.33 \\
1.44 \\
1.12 \\
2.15 \\
1.56 \\
1.44\end{array}$ & $\begin{array}{r}-33 \\
0 \\
-2 \\
+23 \\
-11 \\
+2 \\
-6 \\
-4 \\
-2 \\
+3 \\
-11 \\
-7 \\
-7 \\
-12 \\
-10 \\
-3\end{array}$ & $\begin{array}{l}1.14 \\
0.5 \\
0.5 \\
3.9 \\
2.3\end{array}$ & $\begin{array}{r}-10 \\
-12 \\
-19 \\
+42 \\
-37 \\
-2 \\
0 \\
-14\end{array}$ & $\begin{array}{l}0.7 \\
0.6 \\
0.13 \\
0.75 \\
0.47 \\
0.51 \\
0.55 \\
0.3 \\
0.3 \\
0.19 \\
0.29 \\
0.44 \\
0.73 \\
1.54 \\
0.8 \\
0.4\end{array}$ & $\begin{array}{r}-65 \\
+27 \\
-43 \\
-7 \\
-11 \\
-19 \\
-27 \\
-54 \\
-6 \\
-9 \\
-21 \\
-2 \\
-29 \\
-10 \\
-33 \\
-6\end{array}$ \\
\hline
\end{tabular}

All measurements are in $\mathrm{mm} . \mathrm{Hg}$ :

Sex: All women, except Case 6.

Heart rhythm: Sinus rhythm in Cases 1, 2, 3, 4, 6, 7, 10,11, 13, and 16; atrial fibrillation in the remainder.

Diagnosis: In Cases 1 to 10 the mitral valve lesion was stenotic: trivial aortic stenosis was present in Case 7. Cases 11 and 12 had slight mitral regurgitation: and Case 12 had also aortic and tricuspid regurgitation. Mitral regurgitation was the sole lesion in Cases 13 to 16.

\section{SUMmaRY}

Venous tourniquets were applied to the legs of sixteen patients with mitral valve disease. Peripheral venous pooling reduced left atrial mean pressure, and altered the contour of the pressure pulse. The pressure at $v$ was lowered by a relatively greater amount than the pressure at $z$; and 
the rate of $y$ descent became less steep. These changes were attributed to a reduction in the flow of blood through the atrium.

The possible diagnostic and therapeutic implications of the study are discussed.

This work was begun in the General Infirmary at Leeds, England, and completed in the Clinic of Surgery, National Heart Institute, Bethesda, Md., U.S.A. The author wishes to express his gratitude to Mr. G. H. Wooler for making the whole study possible; and to thank Mr. G. H. Wooler, Mr. K. Lawrance, Mr. J. Shoesmith, and Dr. L. R. Radigan for their expert bronchoscopies in Leeds.

Several of the left atrial pressure pulse studies were made in the National Heart Institute; and the author is deeply grateful to the Director for the opportunity afforded him to work as Guest Scientist in the Clinic of Surgery; and to Dr. A. G. Morrow and Dr. E. Braunwald for their generous co-operation in the performance of left heart catheterization. The technical assistance of Mr. S. E. Sieniewicz at the General Infirmary, Leeds, and of Mr. Frederick Bullock and his assistants at the National Heart Institute is gratefully acknowledged.

\section{REFERENCES}

Allison, P. R., and Linden, R. J. (1955). Lancet, 1, 9.

Carlsten, A., and Grimby, G. (1958). Scand. J. clin. Lab. Invest., 10, 397.

Connolly, D. C., and Wood, E. H. (1957). J. Lab. clin. Med., 49, 526.

Doyle, J. T., Wilson, J. S., Estes, E. H., and Warren, J. V. (1951). J. clin. Invest., $30,345$.

Ebert, R. V., and Stead, E. A. (1940). J. clin. Invest., 19, 561.

Estes, E. H., and McWhorter, R. L. (1949). Amer. J. Physiol., 159, 568.

Fitzhugh, F. W., McWhorter, R. L., Estes, E. H., Warren, J. V., and Merrill, A. J. (1953). J. clin. Invest., $32,1163$.

Hamer, N. A. J., Roy, S. B., and Dow, J. W. (1959). Circulation, 19, 257.

Hayward, G. W. (1955). Brit. med. J., 1, 1361.

Leonard, J. L., Weissler, A. M., and Warren, J. V. (1958a). Brit. Heart J., 10, 502.

$-1,-1, \ldots$ (1958b). Circulation, 17, 1007.

McMichael, J., and Sharpey-Schafer, E. P. (1944). Brit. Heart J., 6, 33.

Morrow, A. G., Braunwald, E., Haller, A. J., and Sharp, E. H. (1957a). Circulation, 16, 399.

$\longrightarrow, \bar{C},-1$ (1957b). Circulation, 16, 1033.

Owen, S. G., and Wood, P. (1955). Brit. Heart J., 17, 41.

Peterson, L. H. (1954). Circulation Research, 2, 127.

Ross, J. Jr. (1959). Ann. Surg., 149, 395.

Rubin, R., and Shah, S. (1958). Amer. Heart J., 55, 55.

Sloan, A. W., and Wishart, M. (1953). Brit. Heart. J., 15, 25.

Warren, J. V., and Stead, E. A. (1943). Amer. J. med. Sci., 205, 501.

- Brannon, E. S., Stead, E. A., and Merrill, A. J. (1945). J. clin. Invest., 24, 337.

Wood, J. E., and Eckstein, J. W. (1958). J. clin. Invest., 37, 41. 